\title{
Spin trapping studies of essential oils in lipid systems
}

\author{
Katerina Makarova, \\ Kinga Drązikowska, \\ Beata Suska, \\ Katarzyna Zawada, \\ Iwona Wawer
}

\begin{abstract}
In the present work, we report the results of a spin trapping ESR study of four essential oils widely used for skin care products such as creams and bath salts. The studied essential oils are Rosmarini aetheroleum (rosemary), Menthae piperitae aetheroleum (mint), Lavandulae aetheroleum (lavender), and Thymi aetheroleum (thyme). Fenton reaction in the presence of ethanol was used to generate free radicals. The $N$-tert-butyl- $\alpha$-phenylnitrone (PBN) was used as a spin trap. In the Fenton reaction, the rosemary oil had the lowest effect on radical adduct formation as compared to the reference Fenton system. Since essential oils are known to be lipid soluble, we also conducted studies of essential oils in Fenton reaction in the presence of lipids. Two model lipids were used, namely 1,2-dioleoyl-sn-glycero-3-phosphocholine (DOPC) and 1,2-dipalmitoyl-sn-glycero-3-phosphocholine (DPPC). The obtained results suggested that in the presence of DOPC lipids, the - $\mathrm{OH}$ and $\mathrm{PBN} /{ }^{\cdot} \mathrm{CHCH}_{3}(\mathrm{OH})$ radicals are formed in both phases, that is, water and lipids, and all the studied essential oils affected the Fenton reaction in a similar way. Whereas, in the DPPC system, the additional type of PBN/X $\left(a_{N}=16.1 \mathrm{G}, a_{H}=2.9 \mathrm{G}\right)$ radical adduct was generated. DFT calculations of hyperfine splittings were performed at B3LYP/6-311+G(d,p)/EPR-II level of theory for the set of $c$-centered PBN adducts in order to identify $\mathrm{PBN} / \mathrm{X}$ radical.
\end{abstract}

Key words: spin trapping ESR • essential oils • DFT calculations • lipids

K. Makarova ${ }^{\bowtie}$, K. Drązikowska, B. Suska, K. Zawada, I. Wawer

Department of Physical Chemistry,

Faculty of Pharmacy,

Medical University of Warsaw,

1 Banacha Str., 02-097 Warsaw, Poland,

Tel./Fax: +48 2257209 51,

E-mail: kmakarova@wum.edu.pl

Received: 24 September 2014

Accepted: 30 January 2015

\section{Introduction}

Since the middle ages, essential oils have been widely used for virucidal, fungicidal, bactericidal, antiparasitical, insecticidal, medicinal, and cosmetic applications [1]. Nowadays, the use of essential oils as functional ingredients in pharmaceutical, sanitary, cosmetic, agricultural, and food industries is gaining wide interest because of increasing concern about potentially harmful synthetic additives [2]. Within the wide range of the above-mentioned products, there is a common need for natural substances with not only a pleasant smell but also with a preservative action, aimed to avoid lipid deterioration, oxidation, and spoilage by microorganisms. In this case, the essential oils and their components are constantly gaining increasing attention because of their relatively safe status, their wide acceptance by consumers, and their application for potential multipurpose functional use [3].

Essential oils are extracted from various aromatic plants. Because of the mode of extraction, they contain a variety of volatile molecules such as terpenes and terpenoids, phenol-derived aromatic components, and aliphatic components [4].

Generally, essential oils have been widely studied mostly from the viewpoint of their flavor and fra- 
grance chemistry as they are used for flavoring foods, drinks, and cosmetics [5]. However, the essential oils are natural sources of phenolic components, so the investigators are attracted to evaluate their activity as antioxidants or free radical scavengers $[6,7]$.

In the present work, we report the results of a study aimed at comparing radical scavenging properties of four essential oils widely used for skin care products such as creams and bath salts. The studied essential oils are Rosmarini aetheroleum (rosemary), Menthae piperitae aetheroleum (mint), Lavandulae aetheroleum (lavender), and Thymi aetheroleum (thyme). Spin trapping ESR was performed utilizing $N$-tert-butyl- $\alpha$-phenylnitrone (PBN) spin probe. Fenton reaction in the presence of ethanol was used to generate free radicals. Since essential oils are known to be lipid soluble, we also conducted studies of essential oils in Fenton reaction in the presence of 1,2-dioleoyl-sn-glycero-3-phosphocholine (DOPC) and 1,2-dipalmitoyl-sn-glycero-3-phosphocholine (DPPC) as model lipids. The influence of essential oils on the model lipid bilayer structure was also studied.

\section{Materials and methods}

\section{Electron spin resonance}

The ESR measurements were performed on a MiniScope MS 200 spectrometer from Magnettech at room temperature $\left(24 \pm 1^{\circ} \mathrm{C}\right)$ using $50 \mu$ capillary tubes. Typical instrument settings were: sweep width $69 \mathrm{G}$, microwave attenuation $10 \mathrm{~dB}$, modulation amplitude of $0.5 \mathrm{G}$, sweep time $20 \mathrm{~s}$.

\section{Spin trapping ESR}

Fenton reaction was used to generate free radicals. PBN spin trap and DTBN (di-tert-butyl nitroxide) spin probe were obtained from Sigma-Aldrich. Hydrogen peroxide $(30 \%)$ and ferrous sulfate $\left(\mathrm{FeSO}_{4} \cdot 7 \mathrm{H}_{2} \mathrm{O}\right)$ were obtained from POCH (Gliwice, Poland). DOPC and DPPC lipids were obtained from Avanti Polar Lipids as chloroform solution $(25 \mathrm{mg} / \mathrm{ml})$. PBN solution was prepared using PBS buffer ( $\mathrm{pH}$ 7.5), $115 \mu \mathrm{l}$ of $20 \mathrm{mM}$ PBN solution was mixed with $3 \mu \mathrm{l}$ of selected essential oil or of $96 \%$ ethanol (for reference measurements). Then, $3 \mu \mathrm{l}$ of water, $7.5 \mu \mathrm{l}$ of $100 \mathrm{mM}$ $\mathrm{FeSO}_{4}$ solution, and $55 \mu \mathrm{l}$ of $25 \mathrm{mM} \mathrm{H}_{2} \mathrm{O}_{2}$ solution were added. The sample was vortexed for $30 \mathrm{~s}$.

For Fenton reaction in lipids: $236 \mu$ l (DOPC) or $220 \mu \mathrm{l}$ (DPPC) of chloroform solutions of lipids were dried for 24 hours. Then $115 \mu \mathrm{l}$ of $20 \mathrm{mM}$ PBN solution added and vortexed ( $2 \mathrm{~min})$. The sample was then sonicated for $3 \mathrm{~min}$. Then, $3 \mu \mathrm{l}$ of ethanol solution of selected essential oil, $3 \mu \mathrm{l}$ of deionized water (Millipore), $7.5 \mu \mathrm{l}$ of $100 \mathrm{mM} \mathrm{FeSO}_{4}$, and $55 \mu \mathrm{l}$ of $25 \mathrm{mM} \mathrm{H}_{2} \mathrm{O}_{2}$ were added and vortexed for $30 \mathrm{~s}$. The first measurement was performed $105 \mathrm{~s}$ after the addition of $\mathrm{H}_{2} \mathrm{O}_{2}$. The next 20 measurements were performed every $3 \mathrm{~min}$. The following concentrations of ethanol solutions of essential oils were used: lavender $(0.033 \% \mathrm{v} / \mathrm{v})$, rosemary $(0.1 \%$ v/v - Fenton, $0.013 \% \mathrm{v} / \mathrm{v}$ for Fenton in lipids), thyme $(0.001 \% \mathrm{v} / \mathrm{v})$, and $\operatorname{mint}(0.01 \% \mathrm{v} / \mathrm{v})$. The concentration of PBN radical adducts were estimated from the reference measurements of $0.1111 \mathrm{mM}$ (for Fenton reaction) and of $0.0111 \mathrm{mM}$ (for Fenton reaction in the presence of lipids) solutions of DTBN spin probe at the same conditions and spectrometer settings.

\section{Spin probe ESR}

$236 \mu \mathrm{l}$ (DOPC) or $220 \mu \mathrm{l}$ (DPPC) of chloroform solutions of lipids were dried for $24 \mathrm{~h}$. Then $135 \mu \mathrm{l}$ of PBS buffer $(10 \mathrm{mM}, \mathrm{pH}=7.5), 10 \mu \mathrm{l}$ of ethanol solution of essential oil, and $15 \mu \mathrm{l}$ of $7 \mathrm{mM}$ DTBN solution were added, vortexed for $2 \mathrm{~min}$, and then placed into an ultrasound bath for $3 \mathrm{~min}$. Samples were measured immediately after preparation, $1 \mathrm{~h}$, and $24 \mathrm{~h}$.

\section{ESR spectra simulations}

ESR spectra were simulated using EasySpin Toolbox for Matlab utilizing 'garlic' function [8].

\section{DFT calculations}

DFT calculation were performed in Gaussian 09 at Interdisciplinary Centre for Mathematical and Computational Modeling (Warsaw, Poland) under the computational Grant G14-6 [9]. Geometry optimization of $\mathrm{PBN} /{ }^{\cdot} \mathrm{OH}, \mathrm{PBN} /{ }^{\cdot}\left(\mathrm{CH}_{3}\right)_{3}, \mathrm{PBN} /{ }^{\cdot}\left(\mathrm{CH}_{2}\right)_{n} \mathrm{CH}_{3}$ $(n=0: 4)$, and $\mathrm{PBN} /{ }^{\circ} \mathrm{CHCH}_{3}(\mathrm{OH})$ were performed at B3LYP/6-31G level of theory using PCM model for water solvent and two solvent molecules. Hyperfine splittings were calculated at B3LYP//6-311G + (d,p)/ EPR-II level of theory.

\section{Results and discussion}

\section{Spin trapping ESR}

The Fenton reaction in the presence of ethanol was used as a reference system. In this system, two types of PBN radical adducts were identified, namely $\mathrm{PBN} /{ }^{\circ} \mathrm{OH}$ and $\mathrm{PBN} /{ }^{\circ} \mathrm{CHCH}_{3} \mathrm{OH}$ (Fig. 1a), which is in agreement with previously published data [10]. Moreover, $\mathrm{PBN} /{ }^{\circ} \mathrm{CHCH} \mathrm{H}_{3} \mathrm{OH}$ is responsible for $90-95 \%$ of the total ESR signal. With time, the decrease of $\mathrm{PBN} /{ }^{\circ} \mathrm{CHCH}_{3} \mathrm{OH}$ radical adduct signal was responsible for the decrease of the total ESR signal (Fig. 1c). All studied essential oils show high antioxidant activity (Fig. 1b). As the ESR signal decreases too fast to be registered after $105 \mathrm{~s}$ (Fig. 1b), the essential oils were appropriately diluted to slow down the reaction and get comparable results (Fig. 1d). In the systems with essential oils, the same radical adducts $\left(90-95 \%\right.$ of $\mathrm{PBN} /{ }^{\circ} \mathrm{CHCH}_{3} \mathrm{OH}$ and $5-10 \%$ of $\mathrm{PBN} /{ }^{\circ} \mathrm{OH}$ ) were identified as the ones in the reference system. The concentration of PBN radical adducts (calculated from the reference DTBN signal) at $240 \mathrm{~s}$ after adding $\mathrm{H}_{2} \mathrm{O}_{2}$ was compared to 
a)

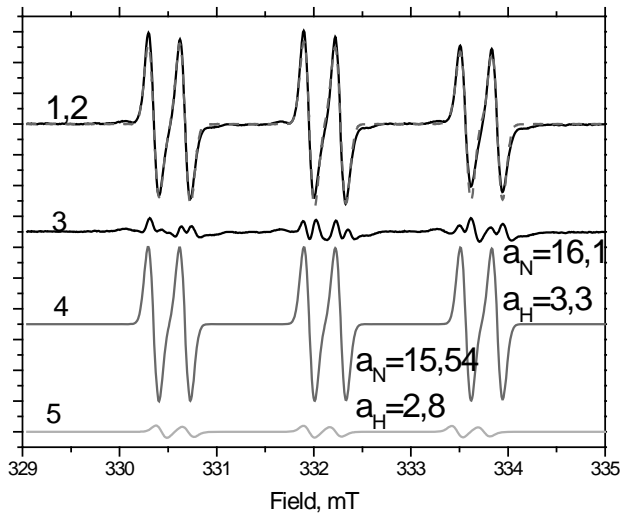

c)

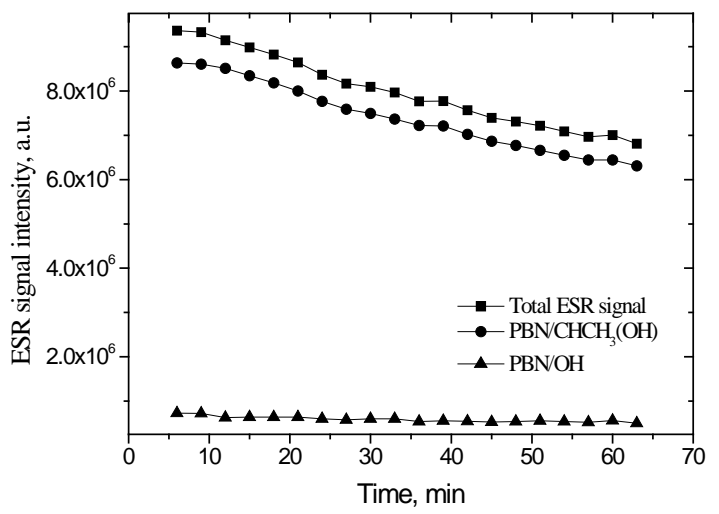

b)

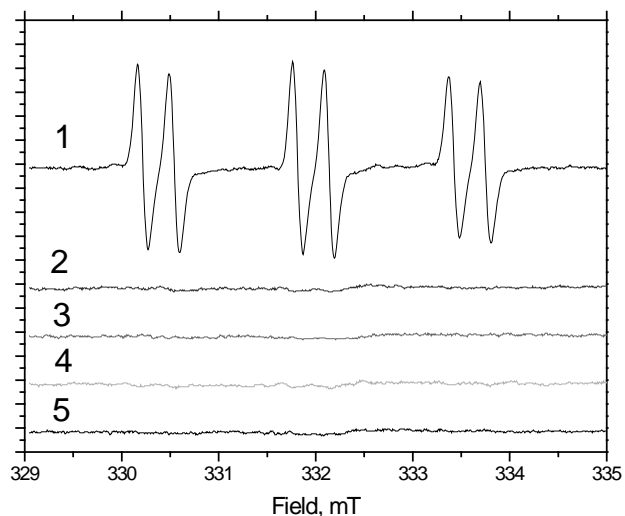

d)

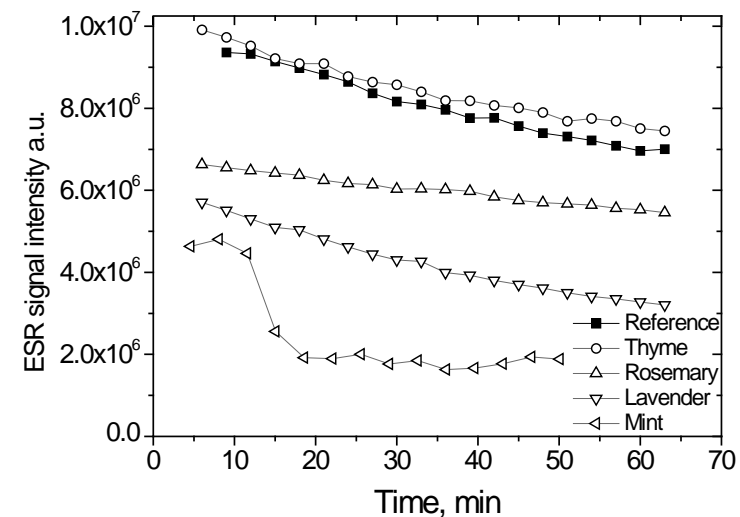

Fig. 1. (a) Experimental (1) and simulated (2) spectra of PBN spin adducts, residuals (3), $\mathrm{PBN} /{ }^{\circ} \mathrm{OH}$ radical adduct component (4), and $\mathrm{PBN} /{ }^{\circ} \mathrm{CHCH}_{3} \mathrm{OH}$ radical adduct component (5). (b) Experimental ESR signal of the spin adducts produced upon the Fenton reaction in the presence of ethanol in reference system (1) and in the presence of essential oils: lavender (2), mint (3), rosemary (4), and thyme (5) after 3 min of the reaction. (c) Kinetics of ESR signal - integrated intensity of spin adducts of PBN that resulted from radicals formed upon the Fenton reaction in the presence of ethanol together with $\mathrm{PBN} /{ }^{\circ} \mathrm{OH}$ and $\mathrm{PBN} /{ }^{\circ} \mathrm{CHCH}_{3} \mathrm{OH}$ components obtained from simulations. (d) Kinetics of ESR signal of radicals formed upon the Fenton reaction in the presence of ethanol and essential oils.

the reference system $\left(c_{\text {PBN_adducts }}=0.09 \mathrm{mM}\right)$. Even though the lavender essential oil has lower concentration $(0.033 \% \mathrm{v} / \mathrm{v})$ than that of rosemary $(0.1 \% \mathrm{v} / \mathrm{v})$, it shows slightly higher antioxidant activity $\left(c_{\text {PBN_adducts }}=\right.$ $0.0555 \mathrm{mM})$ in Fenton reaction than that of rosemary oil $\left(c_{\mathrm{PBN} \_ \text {adducts }}=0.0648 \mathrm{mM}\right)$. Thyme essential oil at $0.05 \% \mathrm{v} / \mathrm{v}$ concentration shows strong antioxidant effect $\left(c_{\mathrm{PBN} \text { adducts }}=0\right)$, whereas its $0.001 \% \mathrm{~V} / \mathrm{v}$ concentration leads to slight prooxidant effect $\left(c_{\mathrm{PBN} \text { adducts }}=\right.$ $0.098 \mathrm{mM})$. The mint essential oil $(0.01 \% \mathrm{v} / \mathrm{v})$ shows strong antioxidant effect $\left(c_{\mathrm{PBN} \text { adducts }}=0.0485 \mathrm{mM}\right)$ as compared to the reference systems.

Taking into account the dilutions of the essential oils, we could conclude that the strongest effect on Fenton reaction was induced by thyme essential oil $(0.05 \% \mathrm{v} / \mathrm{v})$, followed by mint and lavender oils. Rosemary oil has the weakest antioxidant properties. Since essential oils are known to be lipid soluble, we also conducted studies of essential oils in Fenton reaction in the presence of lipids.

\section{Effect of essential oils on lipids}

Prior to Fenton in lipids studies, the effect of essential oils on lipid structure was studied using free spin probe DTBN, which can easily partition into both phases, that is, lipid and water. In this study two model lipids, DOPC and DPPC, were used.
In the reference, DOPC system ratio of DTBN in water and lipid phase was 0.75:0.25 (Fig. 2-IA,B). At first, it is the mint essential oil that has the largest effect on DOPC. However, after $24 \mathrm{~h}$, the strongest effect (larger ratio of DTBN in lipid phase) was observed in DOPC systems with thyme and rosemary essential oils (0.63:0.37 water to lipid ratio) (Fig. 2-IA).

In the case of the second lipid system, DPPC lipids organize into a more rigid structure at room temperature, thus the DTBN is not partitioning into lipid phase in the reference system (Fig. 2-IIA,B). The same situation was observed in the presence of lavender essential oil. Mint and thyme essential oils induce some change in the lipid structure as 30\% of the DTBN spin probes were in lipid phase immediately after sample preparation. After $24 \mathrm{~h}$, that ratio decreased to only $20 \%$ of the spin probes in DPPC lipids (Fig. 2-IIA). The effect of rosemary essential oil was similar to those of mint and thyme oils, but weaker (15\% of DTBN in lipid phase, decreasing to 3\%) (Fig. 2-IIA).

\section{Spin trapping in the presence of lipids}

Based on spin probe ESR results in DOPC lipid systems, we could expect partitioning of Fenton generated free radicals as well as of PBN into lipid bilayer. Here one could expect that PBN would also 


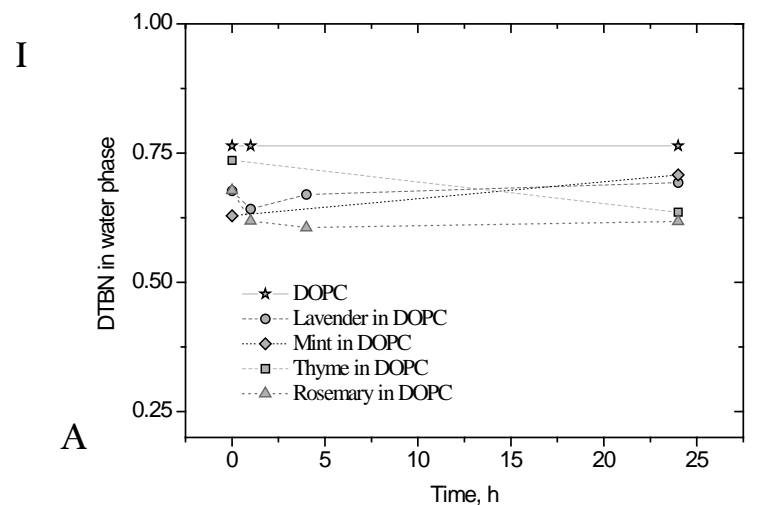

II

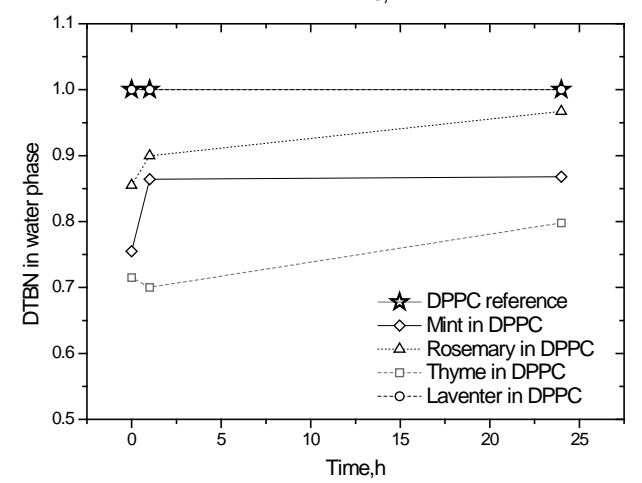

B

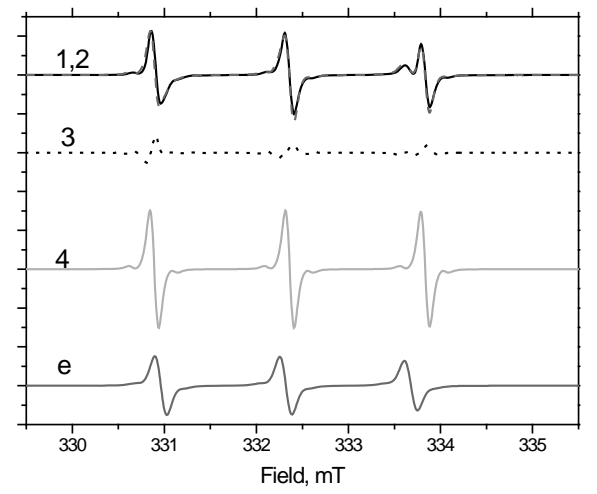

B

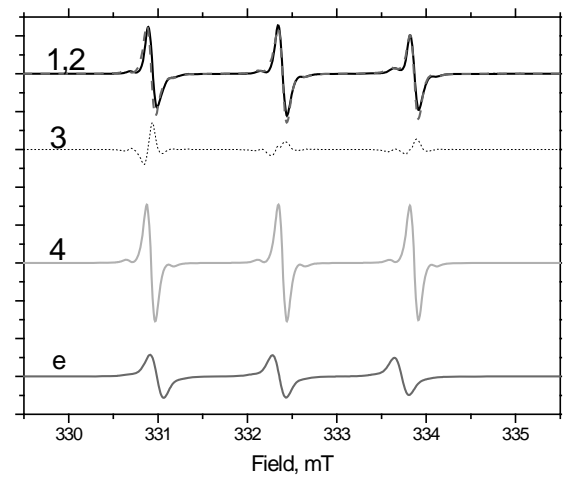

Fig. 2. (A) Ratio of DTBN spin probes in water phase in the reference system and in the presence of essential oils. (B) Experimental (1) and simulated (2) spectra of DTBN spin probe in lipid system with mint essential oil, residuals (3), DTBN in water phase component (4), DTBN in lipid phase component (5). (I) DOPC lipids, (II) DPPC lipids. trap radicals inside the lipid bilayer. The obtained most radicals $\left(c\right.$-centered $(0.0309 \mathrm{mM})$ and ${ }^{\circ} \mathrm{OH}$ results suggested that in the presence of DOPC $(0.0023 \mathrm{mM}))$ are formed in the water phase, in these lipids, the $\mathrm{PBN} /{ }^{\cdot} \mathrm{OH}$ and $\mathrm{PBN} /{ }^{\cdot} \mathrm{CHCH}_{3}(\mathrm{OH})$ radicals are formed in both phases, that is, water and lipids (Table 1, Fig. 3A). Lavender $(0.033 \%$ $\mathrm{v} / \mathrm{v})$, mint $(0.01 \% \mathrm{v} / \mathrm{v})$, and thyme $(0.001 \% \mathrm{v} / \mathrm{v})$ essential oils show similar antioxidant activity (Fig. 3B,D,E,F). The rosemary essential oil $(0.013 \%$ $\mathrm{V} / \mathrm{v})$ reveals prooxidant properties in the presence of DOPC lipids (Fig. 3C). When comparing the systems at the moment of first measurement $(240 \mathrm{~s})$, in contrast to the reference system (Fig. 3B), where systems $\mathrm{PBN} /{ }^{\circ} \mathrm{OH}$ radical adduct concentration in water is much lower (0.0001-0.001 mM) (Table 2). At the same time, there is noticeable increase in $\mathrm{PBN} /{ }^{\cdot} \mathrm{CHCH}_{3} \mathrm{OH}$ concentration in lipid phase, that is, 0.0103 to $0.0239 \mathrm{mM}$ as compared to reference $0.0055 \mathrm{mM}$ (Table 2). The increased concentration of spin adducts in lipid phase in the presence of essential oils correlates with the increase of DTBN partitioning in the same systems, that is, it could be explained by more fluid DOPC lipid structure.

Table 1. Experimental hyperfine splittings of PBN adducts in DOPC and DPPC systems

\begin{tabular}{|c|c|c|c|c|c|c|}
\hline Spin adduct & \multicolumn{6}{|c|}{ Hyperfine splitting, G } \\
\hline System & \multicolumn{4}{|c|}{ DOPC } & \multirow{2}{*}{\multicolumn{2}{|c|}{$\begin{array}{l}\text { DPPC } \\
\text { water }\end{array}$}} \\
\hline \multirow{2}{*}{ Phase } & \multicolumn{2}{|c|}{ water } & \multicolumn{2}{|c|}{ lipid } & & \\
\hline & $a_{N}$ & $a_{H}$ & $a_{N}$ & $a_{H}$ & $a_{N}$ & $a_{H}$ \\
\hline$\overline{\mathrm{PBN} /{ }^{\circ} \mathrm{CHCH}_{3}(\mathrm{OH})}$ & 16.10 & 3.3 & 14.10 & 3.35 & 16.10 & 3.3 \\
\hline $\mathrm{PBN} / \cdot \mathrm{OH}$ & 15.54 & 2.8 & 14.46 & 2.74 & 15.54 & 2.8 \\
\hline $\mathrm{PBN} / \mathrm{X}$ & & & & & 16.10 & 2.9 \\
\hline
\end{tabular}

Table 2. Concentrations of PBN radical adducts at $240 \mathrm{~s}$ of the Fenton reaction in water and lipid (DOPC) phases in the presence of essential oils

\begin{tabular}{lccccc}
\hline \multirow{2}{*}{$\begin{array}{c}\text { System } \\
\text { of study }\end{array}$} & \multirow{2}{*}{$\begin{array}{c}\text { Total } \\
\text { concentration } \\
\text { of PBN radical } \\
\text { adducts }[\mathrm{mM}]\end{array}$} & \multicolumn{2}{c}{ Water phase } & DOPC lipid phase \\
\cline { 3 - 6 } & 0.0444 & 0.03090 & 0.0023 & 0.0055 & $\mathrm{PBN} /{ }^{\circ} \mathrm{CHCH}_{3}(\mathrm{OH})$ \\
\hline Reference & 0.0469 & 0.02256 & 0.0007 & 0.0139 & 0.0057 \\
Lavender & 0.0452 & 0.02690 & 0.0009 & 0.0105 & 0.0068 \\
Mint & 0.0428 & 0.02170 & 0.0004 & 0.0103 & 0.0104 \\
Thyme & 0.0818 & 0.04530 & 0.0001 & 0.0239 & 0.0125 \\
Rosemary & & &
\end{tabular}




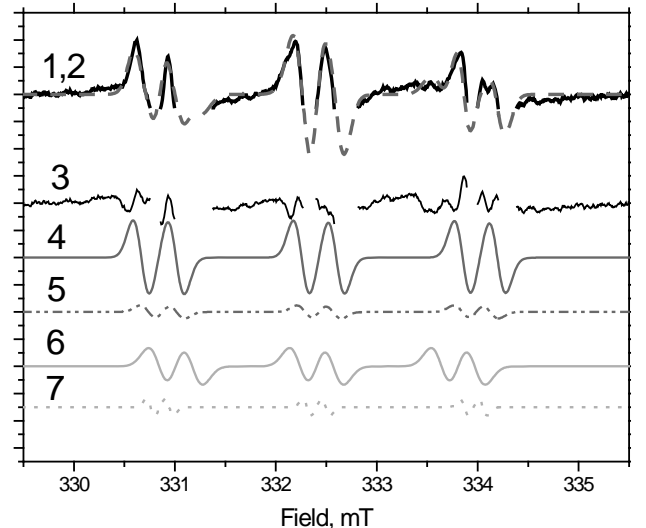

A. reference DOCP

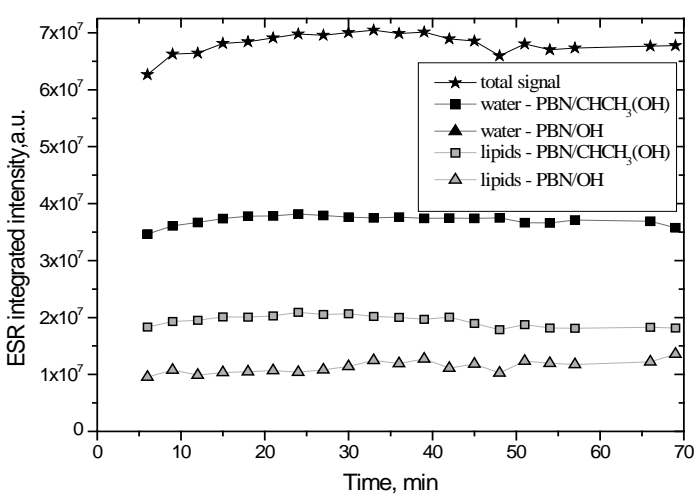

C. rosemary

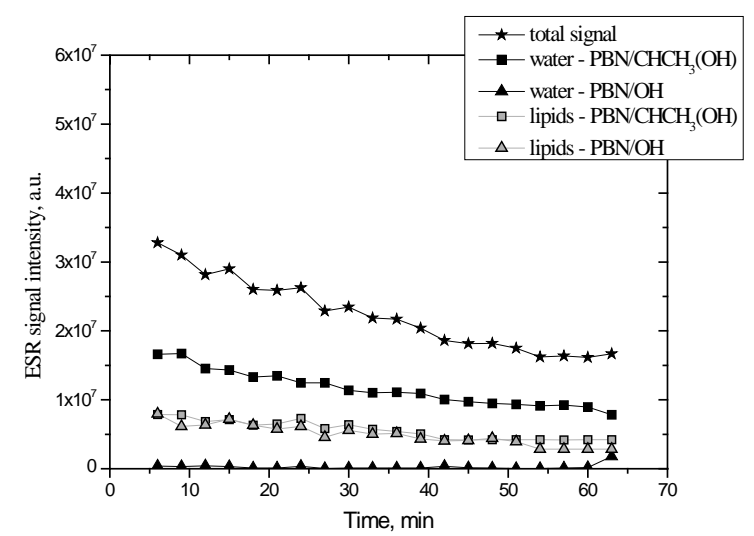

E. thyme

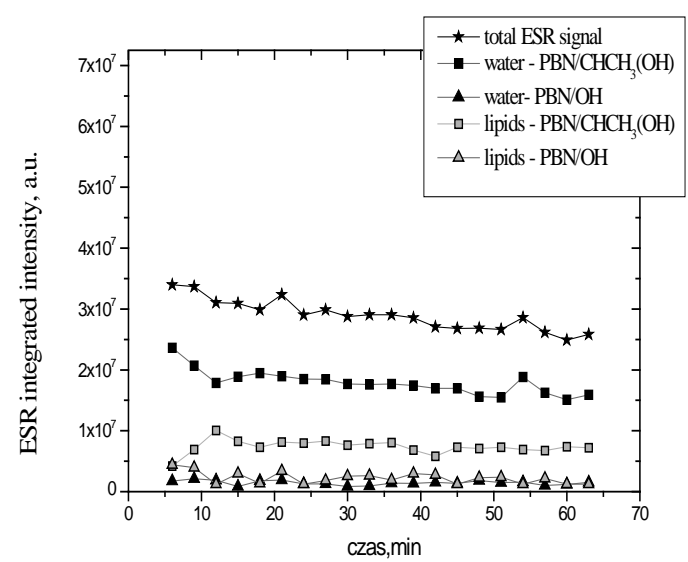

B. reference DOCP

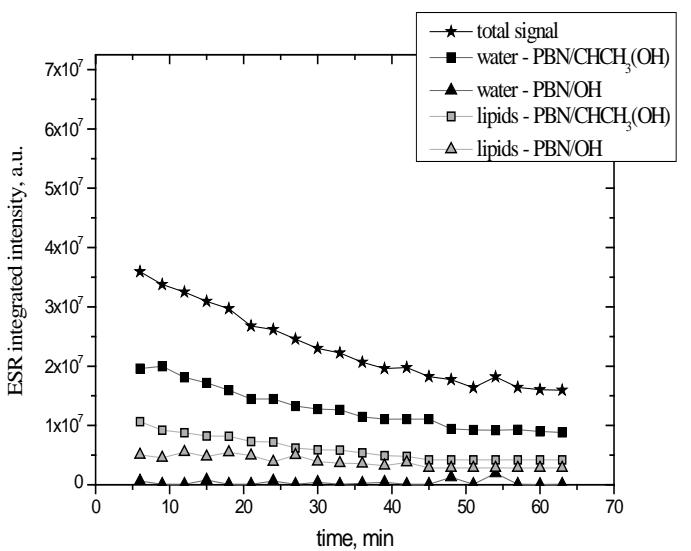

D. lawender

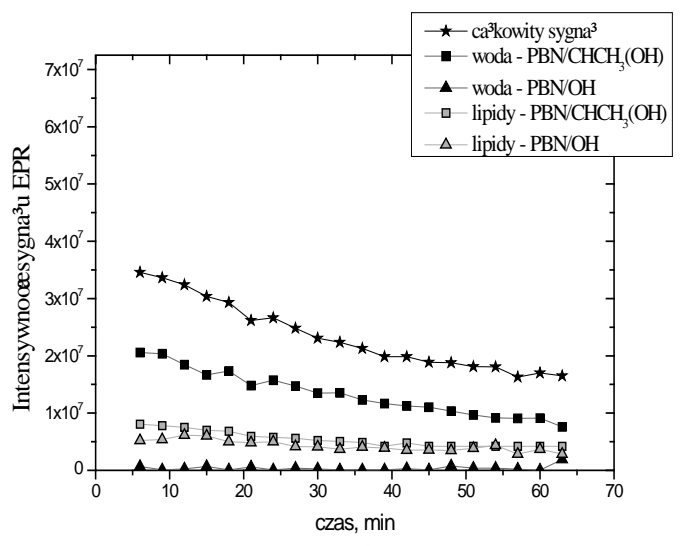

F. mint

Fig. 3. (A) Experimental (1) and simulated (2) spectra of PBN spin adducts produced upon the Fenton reaction in DOPC lipids reference system and residuals (3), $\mathrm{PBN} /{ }^{\circ} \mathrm{OH}(4)$ and $\mathrm{PBN} /{ }^{\circ} \mathrm{CHCH} \mathrm{HCH}_{3} \mathrm{O}$ (5) radical adduct component in water phase, $\mathrm{PBN} /{ }^{\cdot} \mathrm{OH}(6)$ and $\mathrm{PBN} /{ }^{\cdot} \mathrm{CHCH}_{3} \mathrm{OH}(7)$ radical adducts components in lipid phase. (B-F) Kinetics of ESR signal integrated intensity of spin adducts of PBN that resulted from radicals formed upon the Fenton reaction in DOPC lipids system in reference system (B) and in the presence of rosemary (C), lavender (D), thyme (E), and mint $(\mathrm{F})$ essential oils.

Partitioning of PBN into DPPC is highly unlikely at room temperature (below its phase transition), as PBN is a larger molecule than DTBN. In Fenton reaction, the presence of $\mathrm{DPPC} \mathrm{PBN} /{ }^{\circ} \mathrm{OH}$ and $\mathrm{PBN} /{ }^{\cdot} \mathrm{CHCH}_{3}(\mathrm{OH})$ radicals were observed in the water phase. However, the additional PBN/X radical adduct was also observed in all systems with DPPC lipids (Fig. 4, Table 3) at different concentrations. It could be located in the water environment as suggested by the large value of $a_{N}$ splitting $(16.1 \mathrm{G})$ (Table 1$)$. The highest concentration of $\mathrm{PBN} / \mathrm{X}$ radical adduct was observed in DPPC system with mint essential oil (Fig. 4C). The lowest concentration $(0.0007 \mathrm{mM})$ of PBN/X was observed in lipid system with thyme essential oil (Table 3, Fig. 4D). Also, in the presence of lavender and rosemary essential oils, the systems appeared to be stabilized as compared with reference DPPC system (Fig. 4E,F).

It seems possible that $\mathrm{X}$ is part of the oxidized DPPC lipid. It was shown that during the oxidation process in DPPC lipid molecule, only hydrogen abstraction could occur, leading to formation of 
Table 3. PBN adducts concentrations at $240 \mathrm{~s}$ of reaction in Fenton reaction in the presence of DPPC lipids

\begin{tabular}{|c|c|c|c|c|}
\hline System of study & $\begin{array}{l}\text { Total concentration } \\
\text { of PBN radical adducts } \\
{[\mathrm{mM}]}\end{array}$ & $\mathrm{PBN} /{ }^{\bullet} \mathrm{OH}$ & $\mathrm{PBN} /{ }^{\bullet} \mathrm{CHCH}_{3}(\mathrm{OH})$ & $\mathrm{PBN} / \mathrm{X}$ \\
\hline Reference & 0.0107 & 0.0410 & 0.0013 & 0.0053 \\
\hline Lavender & 0.0057 & 0.0001 & 0.0019 & 0.0030 \\
\hline Mint & 0.0060 & 0.0025 & 0.0007 & 0.0029 \\
\hline Thyme & 0.0048 & 0.0018 & 0.0023 & 0.0007 \\
\hline Rosemary & 0.0050 & 0.0014 & 0.0014 & 0.0022 \\
\hline
\end{tabular}

various length aliphatic radicals [11]. On the other hand, the PBN adduct with similar hyperfine splittings $\left(a_{N}=16.1\right.$ and $\left.a_{H}=2.9\right)$ was observed in Fenton system together with $\mathrm{PBN} /{ }^{\circ} \mathrm{OH}$, however it was not identified [10]. We could assume that $\mathrm{PBN} / \mathrm{X}$ adduct in both cases is a $c$-centered radical

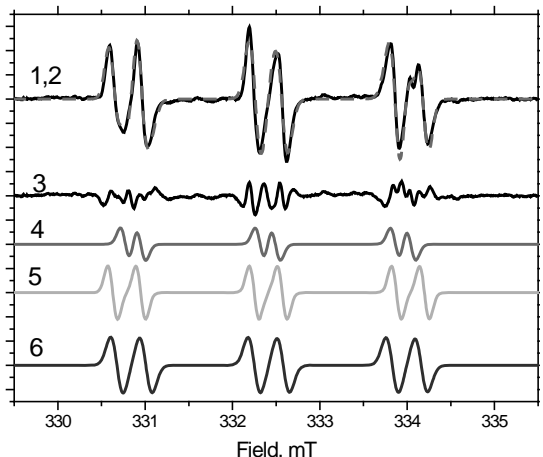

A. reference DPPC

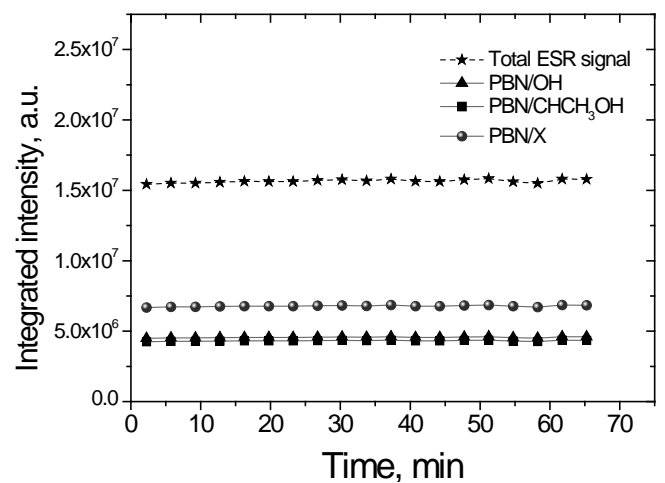

C. rosemary

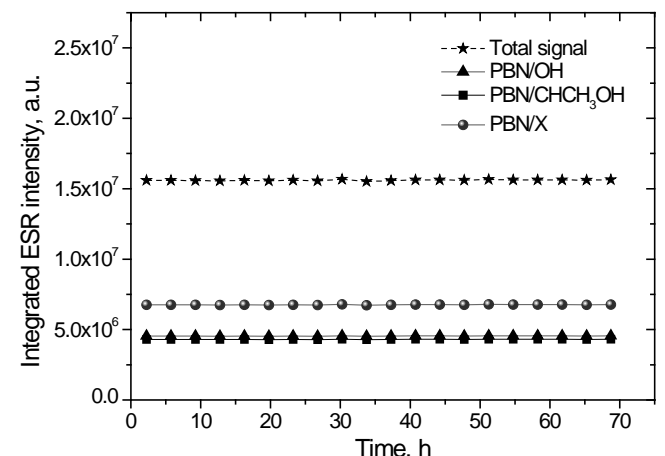

E. lavender originating either from decomposition of PBN spin probe or DPPC lipid oxidation (both reaction could lead to $c$-centered radical formation). However, PBN splitting pattern is not very sensitive to $c$-centered radical structure [10].
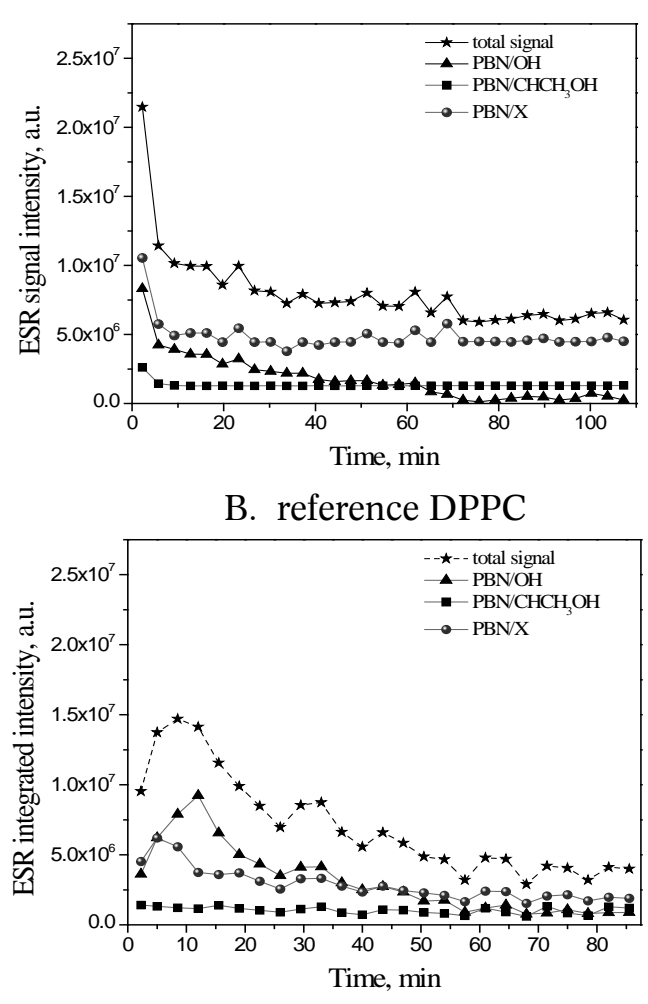

D. thyme

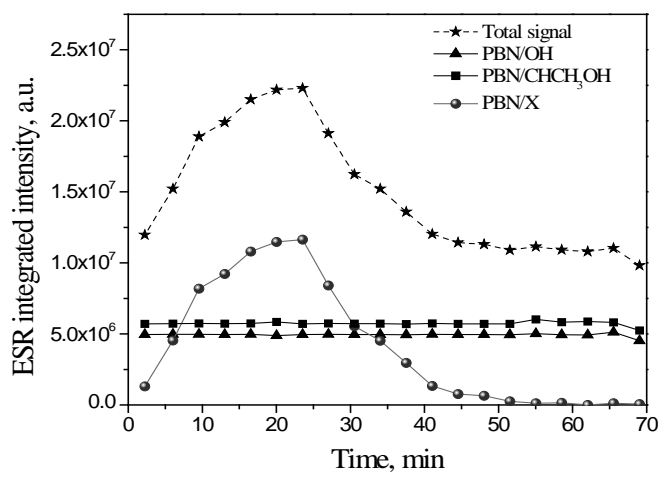

F. mint

Fig. 4. (A) Experimental (1) and simulated (2) spectra of PBN spin adducts produced upon the Fenton reaction in DPPC lipids system in the presence of ethanol, residuals (3); $\mathrm{PBN} /{ }^{\cdot} \mathrm{OH}(4) ; \mathrm{PBN} /{ }^{\cdot} \mathrm{CHCH}_{3} \mathrm{OH}(5)$ and $\mathrm{PBN} / \mathrm{X}(6)$ radical adduct components. (B-F) Kinetics of ESR signal integrated intensity of spin adducts of PBN that resulted from radicals that were formed upon the Fenton reaction in DPPC lipids system in reference system (B) and in the presence of rosemary (C), thyme (D), lavender (E), and mint (F) essential oils. 
Table 4. Hyperfine splitting constants of various PBN spin adducts from DFT calculations at the B3LYP//6-311+G(d,p)/ EPR-II level of theory using the PCM model for the water solvent and two water molecules

\begin{tabular}{lcccc}
\hline \multirow{2}{*}{\multicolumn{1}{c}{$\mathrm{EPR}$}} & \multicolumn{3}{c}{ EPR-II } & \multicolumn{2}{c}{$6-311+\mathrm{G}(\mathrm{d}, \mathrm{p})$} \\
\cline { 2 - 5 } & $a_{N}$ & $a_{H}$ & $a_{N}$ & $a_{H}$ \\
\hline $\mathrm{PBN} /{ }^{\circ} \mathrm{OH}$ & 13.16077 & 1.13516 & 11.51572 & 1.07258 \\
$\mathrm{PBN} /{ }^{\circ} \cdot \mathrm{CHCH}{ }_{3} \mathrm{OH}$ & 12.20840 & 4.86681 & 10.47146 & 4.64074 \\
$\mathrm{PBN} /{ }^{\circ}\left(\mathrm{CH}_{2}\right)_{4} \mathrm{CH}_{3}$ & 13.26373 & 0.21139 & 11.43028 & 0.21751 \\
$\mathrm{PBN} /{ }^{\prime}\left(\mathrm{CH}_{2}\right)_{3} \mathrm{CH}_{3}$ & 13.70019 & 0.06914 & 11.87515 & 0.09204 \\
$\mathrm{PBN} / \cdot\left(\mathrm{CH}_{2}\right)_{2} \mathrm{CH}_{3}$ & 13.67142 & 0.06750 & 11.84538 & 0.09108 \\
$\mathrm{PBN} /{ }^{\circ} \mathrm{CH}_{2} \mathrm{CH}_{3}$ & 13.69387 & 0.08547 & 11.86356 & 0.11929 \\
$\mathrm{PBN} / \cdot \mathrm{CH}_{3}$ & 13.77089 & 0.06759 & 11.94251 & 0.09022 \\
$\mathrm{PBN} /{ }^{\circ}\left(\mathrm{CH}_{3}\right)_{3}$ & 12.20162 & 2.58752 & 10.43217 & 2.43723 \\
\hline
\end{tabular}

\section{DFT calculations}

Based on the suggested mechanism of DPPC oxidation [11], there is a set of $\cdot\left(\mathrm{CH}_{2}\right)_{n} \mathrm{CH}_{3}$ radicals which could be trapped by PBN. The mechanism of PBN degradation was proposed by [12] and lead to the formation of $t$-BuNO, which subsequently decomposes to $\mathrm{NO}^{*}$ and $t$ - $\mathrm{Bu}^{*}$.

In order to perform the identification of the observed $\mathrm{PBN} / \mathrm{X}$ radical adduct, the hyperfine splittings of PBN $/{ }^{\circ}\left(\mathrm{CH}_{2}\right)_{n} \mathrm{CH}_{3}(n=0: 4), \mathrm{PBN} /{ }^{\cdot}\left(\mathrm{CH}_{3}\right)_{3}$, $\mathrm{PBN} /{ }^{\circ} \mathrm{CHCH}_{3} \mathrm{OH}$, and $\mathrm{PBN} /{ }^{\circ} \mathrm{OH}$ were calculated (Table 4). The solvent effect was accounted by PCM model and two water molecules [13]. The previous studies showed that B3LYP//6-311+G(d,p)/EPR-II basis are the most accurate for PBN adducts calculations $[13,14]$, however $1-2 \mathrm{G}$ difference is still produced. Previous studies suggest the evaluation of the trend in hyperfine splitting's (correlation plot) rather than direct comparison [14]. The DFT calculations reveal similar values for the whole set of PBN/ $\cdot\left(\mathrm{CH}_{2}\right)_{n} \mathrm{CH}_{3}$ radicals (Table 4) as well as similar values for $\mathrm{PBN} /{ }^{\cdot} \mathrm{CHCH} \mathrm{HHH}_{3} \mathrm{O}$ and $\mathrm{PBN} /{ }^{\cdot}\left(\mathrm{CH}_{3}\right)_{3}$ radical adducts. Since the experimental hyperfine values of $\mathrm{PBN} / \mathrm{X}$ radical adduct is close to that of $\mathrm{PBN} /{ }^{\circ} \mathrm{CHCH} \mathrm{H}_{3} \mathrm{OH}$, we could suggest that the observed radical adduct is $\mathrm{PBN} /{ }^{\bullet}\left(\mathrm{CH}_{3}\right)_{3}$. However, the additional experiments with another spin trap with more specific splitting pattern for $c$-centered radicals are necessary.

\section{Conclusions}

Spin trapping studies of interactions of essential oils with radicals produced in Fenton reaction showed that the presence of essential oils generally decreased the amount of radical adducts formed, but did not change the type of radicals formed. The weakest effect on radical adducts formation was observed for rosemary essential oil. In the presence of DOPC and DPPC lipids systems, rosemary essential oil stabilized the trapping of radicals, that is, ESR integrated intensity as well as ratio of the radical adduct components remind the same with time. Also, in the presence of DOPC lipids two radical adducts $\left(\mathrm{PBN} /{ }^{\circ} \mathrm{OH}\right.$ and $\left.\mathrm{PBN} /{ }^{\circ} \mathrm{CHCH}_{3} \mathrm{OH}\right)$ in two phases (water and lipid) were identified. Whereas in the case of the DPPC lipids, all radicals appeared to be in water phase. In addition to $\mathrm{PBN} /{ }^{\circ} \mathrm{OH}$ and
$\mathrm{PBN} /{ }^{\circ} \mathrm{CHCH}_{3} \mathrm{OH}$ radical adducts, the new $\mathrm{PBN} / \mathrm{X}$ radical adduct was observed in the presence of DPPC. Based on DFT calculations, this PBN/X radical could originate from the decomposition of PBN spin trap.

\section{References}

1. Bakkali, F., Averbeck, S., Averbeck, D., \& Idaomar, M. (2008). Biological effects of essential oils - a review. Food Chem. Toxicol., 46, 446-475.

2. Reische, D., Lillard, D., Eitenmiller, R., Akoh, C., \& Min, D. (1998). Antioxidants. In C. C. Akoh \& D. B. Min (Eds.), Food lipids: chemistry, nutrition and biotechnology, 3rd ed. (pp. 409-433). Boca Raton: CRC Press.

3. Ormancey, X., Sisalli, S., \& Coutiere, P. (2001). Formulation of essential oils in functional perfumery. Parfums, Cosmetiques, Actualites, 157, 30-40.

4. Edris, A. E. (2007). Pharmaceutical and therapeutic potentials of essential oils and their individual volatile constituents: a review. Phytother. Res., 21, 308-323.

5. Smith, R., Cohen, S., Doull, J., Feron, V., Goodman, J., Marnett, L., Portoghese, P., Waddell, W., Wagner, B., \& Hall, R. (2005). A procedure for the safety evaluation of natural flavor complexes used as ingredients in food: essential oils. Food Chem. Toxicol., 43, 345-363.

6. Burt, S. (2004). Essential oils: their antibacterial properties and potential applications in foods - a review. Int. J. Food Microbiol., 94, 223-253.

7. Sacchetti, G., Maietti, S., Muzzoli, M., Scaglianti, M., Manfredini, S., Radice, M., \& Bruni, R. (2005). Comparative evaluation of 11 essential oils of different origin as functional antioxidants, antiradicals and antimicrobials in foods. Food Chem., 91, 621-632.

8. Stoll, S., \& Schweiger, A. (2006). EasySpin, a comprehensive software package for spectral simulation and analysis in EPR. J. Magn. Reson., 178, 42-55.

9. Frisch, M. J., Trucks, G. W., Schlegel, H. B., Scuseria, G. E., Robb, M. A., Cheeseman, J. R., Montgomery, J. A. Jr, Vreven, T., Kudin, K. N., Burant, J. C., Millam, J. M., Iyengar, S. S., Tomasi, J., Barone, V., Mennucci, B., Cossi, M., Scalmani, G., Rega, N., Petersson, G. A., Nakatsuji, H., Hada, M., Ehara, M., Toyota, K., Fukuda, R., Hasegawa, J., Ishida, M., Nakajima, T., Honda, Y., Kitao, O., Nakai, H., Klene, M., Li, X., Knox, J. E., Hratchian, H. P., Cross, J. B., Adamo, C., Jaramillo, J., Gomperts, R., Stratmann, R. E., Yazyev, O., Austin, A. J., Cammi, R., Pomelli, C., Ochterski, J. W., Ayala, P. Y., Morokuma, K., Voth, G. A., Salvador, P., Dannenberg, J. J., Zakrzewski, V. G., Daniels, A. D., Farkas, O., Rabuck, A. D., Raghavachari, K., \& Ortiz, J. V. (2009). Gaussian 03, Revision C.02. Wallingford CT: Gaussian, Inc. 
10. Buettner, G. R. (1987). Spin trapping: ESR parameters of spin adducts 1474 1528V. Free Radic. Biol. Med., 3, 259-303.

11. Dilbeck, C. W., \& Finlayson-Pitts, B. J. (2013). Hydroxyl radical oxidation of phospholipid-coated $\mathrm{NaCl}$ particles. Phys. Chem. Chem. Phys., 15, 9833-9844.

12. Chamulitrat, W., Parker, C. E., Tomer, K. B., \& Mason, R. P. (1995). Phenyl N-tert-butyl nitrone forms nitric oxide as a result of its $\mathrm{Fe}(\mathrm{III})$-catalyzed hydrolysis or hydroxyl radical adduct formation. Free Radic. Res., 23, 1-14.
13. Jerzykiewicz, M., Ćwielagg-Piasecka, I., Witwicki, M., \& Jezierski, A. (2010). EPR spin trapping and DFT studies on structure of active antioxidants in biogycerol. Chem. Phys. Lett., 497, 135-141.

14. Ucun, F., \& Aydın, S. G. (2014). Calculated optimized structures and hyperfine coupling constants of some radical adducts of $\alpha$-phenyl-N-tert-butyl nitrone in water and benzene solutions. J. Organomet. Chem., 759, 27-32. 